\title{
Science communication methods and strategies for paleoscientists
}

\author{
Heather Plumpton', Y. Ait Brahim², E.J. Gowan ${ }^{3}$ and E.P. Dassié ${ }^{4}$
}

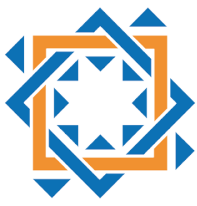

PAGES Morillo de Tou 2017

3rd Young Scientists Meeting

Global Challenges for our Common Future

a paleoscience perspective

Why communicate our science? Aside from our duty to let taxpayers, who largely fund our research, know what their money has been spent on, our motivation to communicate stems mainly from a desire to make a contribution towards a more sustainable world. Given the scale of the environmental challenges facing the planet and human societies today, doing only research is not enough. There is a clear need for us, as scientists, and even more as early-career scientists, to communicate to a wider audience than just our direct peers.

But how do we go about doing that? We can write press releases and hope that journalists will pick up the story. This can be an effective way to reach a wide audience, but control of the story is lost once you put the press release out. Additionally, we can utilize social media by writing blog posts, promoting ourselves and our work through Twitter, or even making YouTube science documentaries. Video media can be an excellent way of making science more accessible to the public, as demonstrated by initiatives such as TED Talks (ted.com).

Engaging with younger generations in science is also very important. For example, going to primary schools and running workshops can be hugely rewarding. However, it is also extremely time consuming to design these activities. Sadly, this time commitment is currently barely recognized or rewarded in terms of career progression. This puts up a significant barrier to early-career scientists doing outreach, as they cannot justify the time commitment in a hyper-competitive job market. Wider recognition of the value of committing time to communicating science to young people is necessary to encourage these activities.

To communicate better to scientific as well as non-scientific audiences, the following suggestions should be considered. Firstly, the art of communication is telling a story. As scientists, we get too easily bogged down in the data, but people need to have an emotional connection to really engage. One way for paleoscientists to do this is to include people in the story, perhaps by talking about and showing images of fieldwork. Secondly, know the audience and keep them in mind throughout. Use the appropriate amount of detail and avoid all jargon. The language barrier must be overcome: it should be adapted to the audience if you don't want to confuse them.
Thirdly, know exactly what you're trying to communicate - be clear about one or two take-home messages. And finally, respond quickly to communications with journalists and do not pass them on to someone more senior. They will then be more likely to continue contacting you in the future.

Overall, despite the importance of communicating science to a broad range of audiences, there is little provision of formal training. This gap in our education could be filled by workshops or seminars organized by the newly proposed PAGES early-career scientists working group.

\section{AFFILIATIONS}

'Department of Geography and Environmental Science, University of Reading, UK

Department of Geology, Ibn Zohr University, Agadir, Morocco

${ }^{3}$ Alfred Wegener Institute, Bremerhaven, Germany LOCEAN/IRD, Paris, France

CONTACT

Heather Plumpton: H.Plumpton@pgr.reading.ac.uk

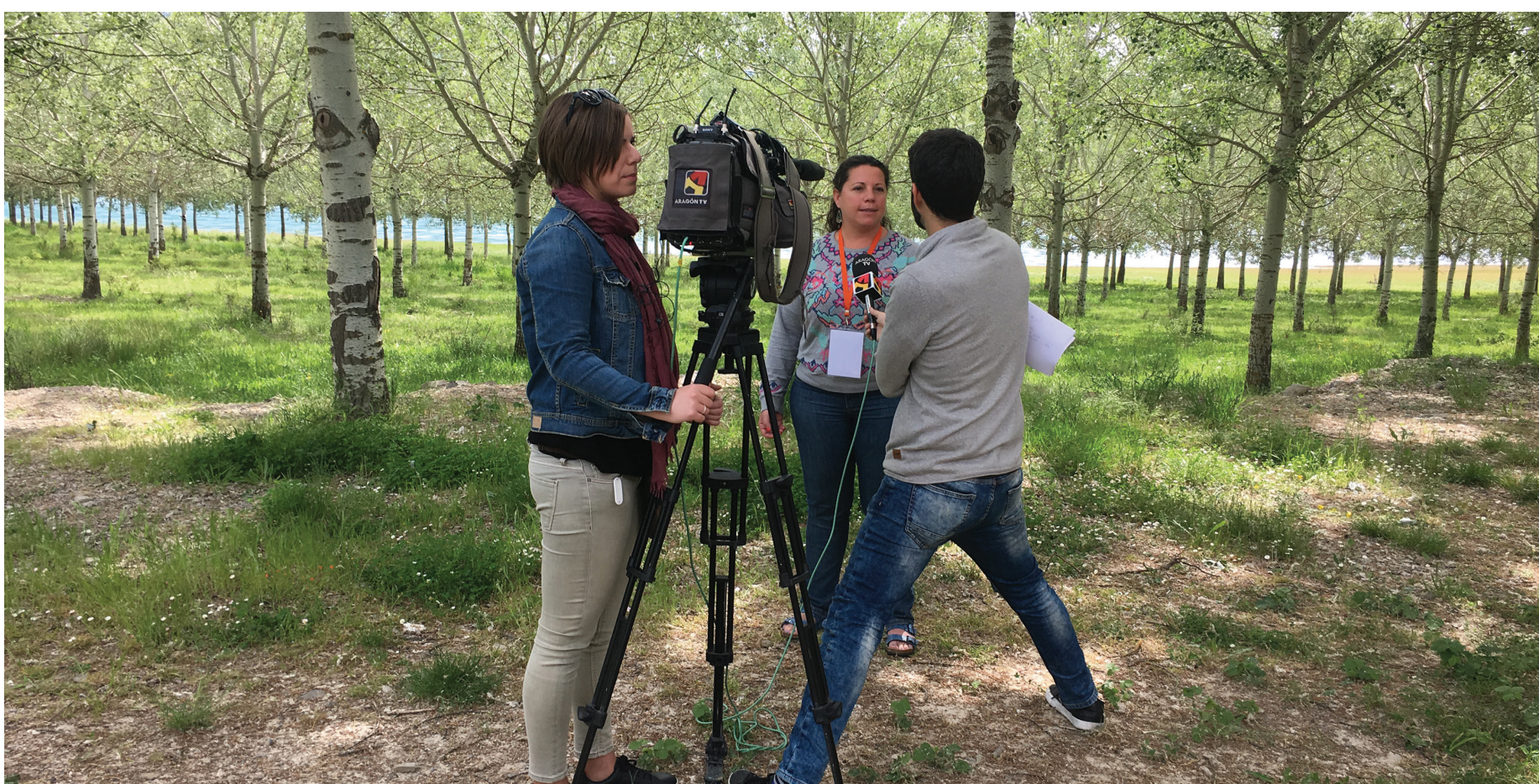

Marie Eugenia de Porras a member of the Scientific Program Committee from Chile, spreads the YSM message on regional Aragonese television. 